\title{
Meteorological Analysis for Clusters of Wind Turbines
}

\author{
D. C. Powell
}

May 1984

Prepared for the U.S. Department of Energy under Contract DE-AC06-76RLO 1830

Pacific Northwest Laboratory Operated for the U.S. Department of Energy by Battelle Memorial Institute 


\section{DISCLAIMER}

This report was prepared as an account of work sponsored by an agency of the United States Government. Neither the United States Government nor any agency thereof, nor any of their employees, makes any warranty, express or implied, or assumes any legal liability or responsibility for the accuracy, completeness, or usefulness of any information, apparatus, product, or process disclosed, or represents that its use would not infringe privately owned rights. Reference herein to any specific commercial product, process, or service by trade name, trademark, manufacturer, or otherwise, does not necessarily constitute or imply its endorsement. recommendation, or favoring by the United States Government or any agency thereof. The views and opinions of authors expressed herein do not necessarily state or reflect those of the United States Government or any agency thereof.

PACIFIC NORTHWEST LABORATORY

operated by

BATTELLE

for the

UNITED STATES DEPARTMENT OF ENERGY

under Contract DE-AC06-76RLO 1830

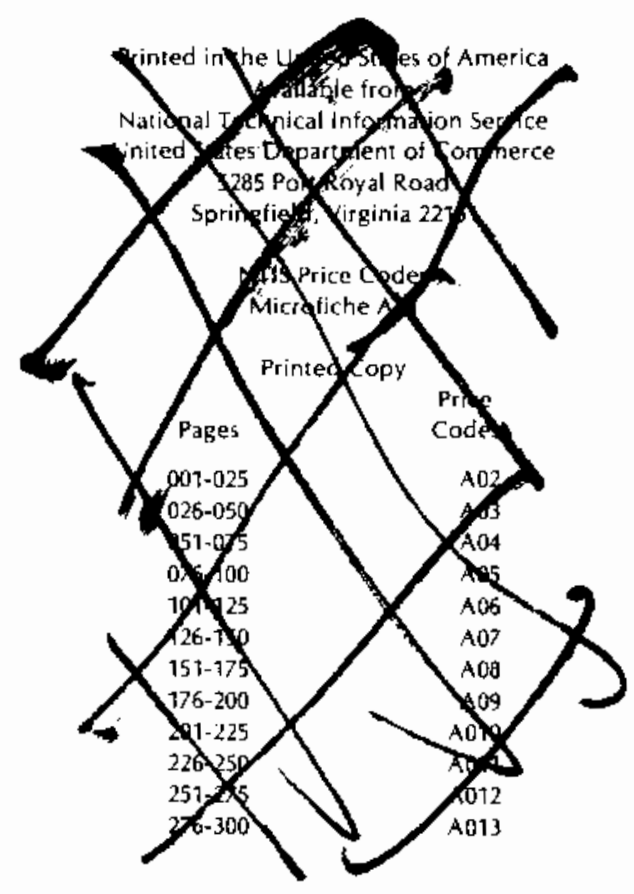


METEOROLOGICAL ANALYSIS FOR

CLUSTERS OF WIND TURBINES

-INTERIM REPORT -

David C. Powell

May 1984

Prepared for

the U.S. Department of Energy

under Contract DE-ACC6-7ERLO 1830

Pacific Northwest Laboratory

Richiand, Washington 99352 
: 


\section{SUMMARY}

A joint research effort by Dr. Sherman Chan and the author aimed at quantifying in a probabilistic framework the load following, operating reserve and unloadable generation requirements for a utility with wind turbine power generation was reported in an EPRI report by Chan et al. (1983) and in a conference paper by Chan, Powell et al. (1983). The present report considers in greater depth important meteorological ideas found in these reports. The meteorological information required for the model by Chan consists of turbulence rms and spatial correlation values subject to certain bandpass and differencing filter specifications.

This report goes beyond the previously published material in the following:

1. A demonstration qualifying the meteorological spectral gap hypothesis is given. It is shown that the peak in the micrometeorological frequency range is at an anomatous level according to a demonstration made using a state-of-the-art micrometeorological spectrum.

2. A spectral model for calculation of rms values for the unstable atmosphere is presented. It is found that theoretically the rms of the unstable atmosphere is about 1.7 times that of the neutral atmosphere when the frequency band considered is one cycle per 30 minutes to one cycle per minute.

3. A spectral model for spatial correlation in neutral conditions is suggested. It is based on Fourier transformation of the abovementioned spectrum. 
$\star$ 


\section{ACKNOWLEDGMENTS}

The basic operational ideas of this report in the first section were developed by Dr. Sherman Chan of Systems Control, Inc. (a) The analysis was a collaborative effort between the author and Dr. Chan, who specified the particular filters used in the analys is to represent time scales of operational importance.

The author also gratefully acknowledges improvements to the manuscript contributed in reviews by Sherman Chan, Robert Schlueter of Michigan State University, George Tennyson of the Department of Energy, and by Al Miller, Harry Wegley, and Elizabeth Owczarski of the Pacific Northwest Laboratory. Sue Schmeck did an excellent job in typing this report.

Finally the author wishes to thank Al Miller for his continuous interest, encouragement and many valuable discussions.

(a) Work at Systems Inc. was sponsored by the Electric Power Research Institute, Contract EPRI AP-3259, Project 1977-1. 

. 


\section{CONTENTS}

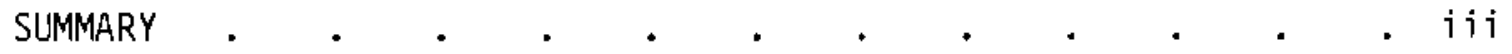

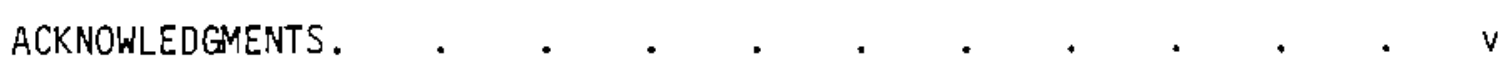

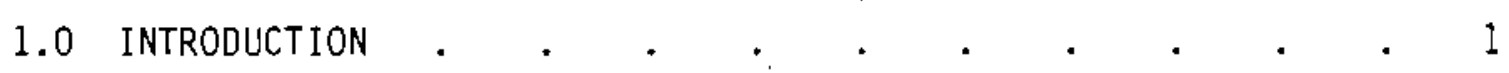

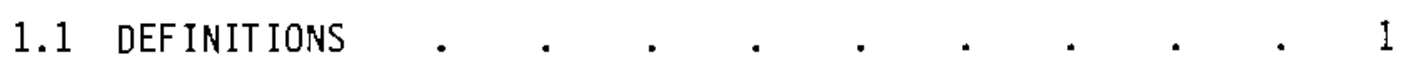

1.1.1 Load Following . . . . . . . . . . 1

1.1.2 Operating Reserve . . . . . . . . . 1

1.1.3 Un loadable Generation . . . . . . . 2

1.2 PURPOSE AND PLACE OF THE PRESENT REPORT . . . . . 3

2.0 THE BASIC PROBLEMS OF ATMOSPHERIC BOUNDARY LAYER TURBULENCE

CHARACTERIZATIDN OF WT ARRAY ANALYSIS IN THE MINUTES

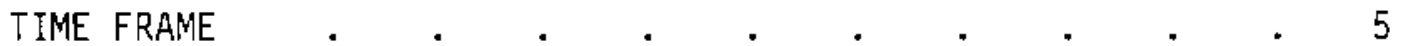

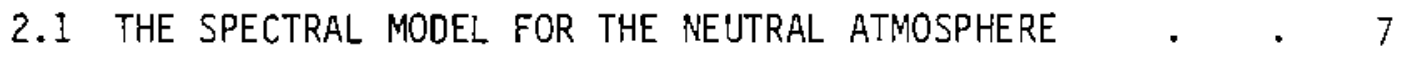

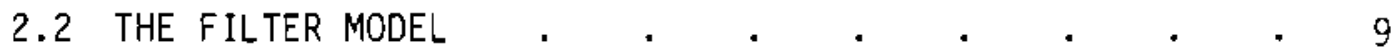

2.3 GENERAL COMMENTS ON THE SPECTRAL MODEL . . . . . 9

2.3.1 Spectral Gap Hypothesis . . . . . 10

2.3.2 On the Use of State-of-the-Art Spectra for the

Alongwind Component of Turbulence . . . 12

3.0 DATA ANALYZED AND SITE CHARACTERISTICS . . . . . . 15

3.1 SITE AND INSTRUMENTATION CHARACTERISTICS • • • 15

3.1.1 Oklahoma PAM Network . . . . . . . 15

3.1 .2 Clayton, New Mexico . . . . . . . 15

3.1.3 WKY Tower . . . . . . . . . . 16

3.1 .4 Goodnoe Hills . . . . . . . . . 16 
3.2 DATA CHARACTERISTICS . . . . . . . . . 16

3.2.1 Ok lahoma PAM Network . . . . . . . 17

3.2 .2 Clayton, New Mexico . . . . . . . . 17

3.2 .3 WKY Tower, OKlahoma . . . . . . 18

3.2.4 Goodnoe Hills $. . \quad . \quad . \quad . \quad . \quad . \quad . \quad . \quad 18$

4.0 RESULTS OF DATA ANALYSIS . . . . . . . . . . . 23

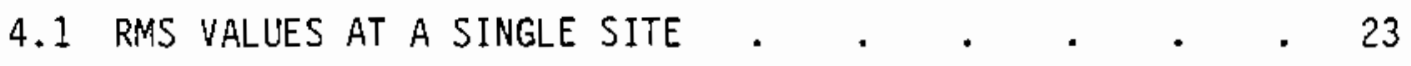

4.1.1 The Unstable Atmosphere . . . . . . 23

4.1.2 The Neutral Atmosphere. . . . . . 24

4.2 ZERO-TIME-LAG SPATIAL CORRELATIONS • • • • . 26

4.2.1 Inter-cluster Separation Distance . . . 26

4.2.2 Inter-WT Separation Distance . . . . 26

5.0 RECOMMENDATIONS. . . . . . . . . . . . . 33

6.0 ReferenCES. . . . . . . . . . . . . . . . 35

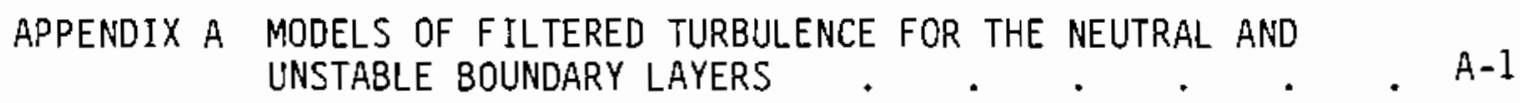

A.1 TURBULENCE INTENSITY MODEL . . . . . . . A-2

A.2 THE SPECTRAL MODEL $\cdot$. . . . . . . . . A-7

A.3 THE FILTER MODEL . . . . . . . . . . A-10

A.4 SENSITIVITY TESTING . . . . . . . . . A-1I 
FIGURES

2.1 Comparison of Kaimal and Kaimal-Frost u Spectra for

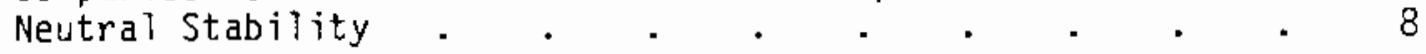

2.2 Reinterpretation of Spectra Gap . . . . . . 10

4.1 Spatial Correlation, Goodnoe Hills, September 1981 • • 28

4.2 Spatial Correlation, Goodnoe Hills, August 1982 . . . 28

4.3 Spatial Correlation, Goodnoe Hills, July, October 1982 . . 29

A.1 Monin-0bukhov L Versus Mean Wind Speed, Unstable
Atmosphere . . . . . . . A-5

A.2 Dimensionless u Spectra, Neutral and Unstable
Atmosphere . . . . . . . A-8

\section{TABLES}

3.1 Starting Times, PAM Data . . . . . . . . 17

3.2 Starting Times, Wind Speed and Direction, Clayton Data . . 17

3.3 Starting Times, wind Speed and Direction and Other

Parameters, WKY Tower Data . . . . . . . . 19

3.4 Starting Times, Wind Speed and Direction for
Goodnoe Hills Data. . . . . . . 21

4.1 RB for Unstable Conditions, WKY Tower . . . . . 24

4.2 RB for Neutral Conditions, WKY Tower . . . . . . 24

4.3 RB for Neutral Conditions, Clayton . . . . . . 24

4.4 Average Value of Spatial Correlations at a Separation
Distance of $674 \mathrm{~m}$ and a Height of $60 \mathrm{~m}$, Goodnoe Hilis . . 27

4.5 Spatial Correlation Lengths and Ratio Between Those Modeled
by Spectral Means and by Exponential Assumption. . 30

A.1 Roughness Lengths (cm) According to Counihan(1975). . . A-3 
A.2 Ratios $U_{\text {ref }} / U(z)$ for selected values of $Z, z_{0}$, and $-L$. A-7

A.3 Suggested Afternoon Values for $z_{i}$. . . . . . . . A-10

A.4 Distinctions between Neutral and Unstable Atmosphere . . A-12 


\subsection{INTRODUCTION}

Electrical power generated by wind turbines (WTs) is a fluctuating quantity. Wind turbines installed in utility grids at first presented little or no operating probiem because of their low penetration. But as the WT penetration increases, the fluctuating nature of wind-generated power will, at some point, significantly affect the dynamic performance of the power system and the cost of operation. The cost is reflected in requirements that are called load following, operating reserve and unloadable generation. These are defined as follows.

\section{I DEFINITIONS}

\subsubsection{Load Following}

A utility system must have adequate load-following capability to satisfy the North American Electric Reliability Council (NERC) operating criteria regarding area control error average values and time between zero crossings, as explained in the NERC Operating Manual, September 1982. To satisfy these critera, with a high WT penetration, the load-following capability of the conventional generators must equal or exceed the rate of change of load plus the rate in change of total generated wind power. A utility's load-following capability is dependent on the ramping capability of its intermediate and peaking generators. In this report the analysis of differenced wind data is used to quant ify the load-following requirement imposed by random wind variation.

\subsubsection{Operating Reserve}

The operating reserve of a utility is defined as the generating capacity above firm load that $c$ an be brought up to meet generation deficiencies caused by load increases, loss of generation and other contingencies. When WTs are installed in a utility grid, the operating reserve must also cover the probable decrease in wind-generated power. 
Generating capacity that makes up the operating reserve is classified as either spinning or nonspinning, depending on whether or not it is synchronized to the power system. The portion of operating reserve that is synchronized can be called on with the least amount of lead time. Nonspinning reserve, depending on the state of readiness, takes 5 to 30 minutes to come online. Due to this large variation in lead time, information on the probable increase in load and decrease in wind-generated power over different spans of time must be known in order to determine the amount of operating reserve required for spinning and nonspinning categories. In this report analysis of undifferenced data was undertaken to quantify operating reserve requirements imposed by random wind variation.

\subsubsection{Unioadable Generation}

A concept analogous to operating reserve is "unloadable generation", which is defined as the amount of online generation capacity that can be backed off to cope with a sudden decrease in load or increase in wind generated power without shutting down any conventional generators see (Lee and Yamayee 1981.)

Chan has developed a method for assessing the utility operating requirements for any given WT penetration, mean wind speed, atmospheric stability, and surface roughness. This method requires turbulence variances and zerotime-lag spatial correlations appropriate for the frequency range of turbulence that is pertinent to the problem. Because wind data that have been averaged by the minute are sufficient for the problem, this analysis is called the minutes time frame. The word turbulence connotes higher frequency wind fluctuations. But for lack of a better word, turbulence will be used to describe wind fluctuations in the minutes time frame in this report. From a meteorological standpoint, this work complements the analysis of a rotating point (Connell 1981) that falls in the seconds time frame. 


\subsection{PURPOSE AND PLACE OF THE PRESENT REPORT}

A joint research effort to quantify in a probabilistic framework the load following, operating reserve, and unloadable generation requirements for a utility with one or more spatially dispersed WT clusters under random atmospheric conditions was first reported by Chan, Powell et al. (1983). An extension of this work is part of a later report by Chan et al. (1983).

The present report will consider, in greater depth, important meteorological ideas in these reports with particular attention to the spatial correlation problem. This report is written so that those without meteorological background can understand the conclusions. However much of the supporting detail and argument is written for the reader with some knowledge of meteorological vocabulary. Most of the meteorological terms are given cursory definition either in the report or in Appendix A. A more extensive reference on turbulence is presented by Panofsky and Dutton (1984). 


\section{$\therefore$}




\subsection{THE BASIC PROBLEMS OF ATMOSPHERIC BOUNDARY LAYER TURBLULENCE CHARAC- TERIZATION OF WT ARRAY ANALYSIS IN THE MINUTES TIME FRAME}

As stated in Section 1.0, the method for computing utility requirements requires turbulence rms values and spatial correlations as they apply in the minutes time frame.

Theoretically, both the rms value and the alongwind spatial correlations can be computed based on the spectral density function of wind turbulence. The spectral density function of a stochastic signal (such as wind) is defined as the average energy content per unit frequency. The spectral properties of turbulence have been studied extensively by micrometeorologists.

The variance, $\sigma^{2}$, is equal to the integral of the spectral density function, $S(n)$, over the entire frequency range:

$$
\sigma^{2}=\int_{0}^{\infty} s(n) d n .
$$

The rms is the square root of the variance. The spectral form most commonly found in the meteorological literature is $n S(n)$, which is the energy content per unit logarithmic frequency. This function can be similarly integrated to yield the variance:

$$
\sigma^{2}=\int_{0}^{\infty} n S(n) d[\ln (n)]
$$

If $F(n)$ represents the filtering applied to the turbulence measurements over the bandwidth of interest, the rms value is given by

$$
\sigma=\left\{\int_{0}^{\infty} n(n) F(n) d[1 n(n)]\right\}^{1 / 2}
$$

Two forms of $F(n)$ are used in this study to model the effects of block averaging, mean removal and differencing operations on the wind speed measurement. To define a model for the spatial correlation, we begin with 
the autocorrelation function and then use Taylor's hypothesis (Taylor 1938) to extend it to the spatial correlation in the alongwind direction. Spatial correlations in other directions are also needed. But there is no theoretical basis for generating them. Experience has shown that the spatial correlation is usually highest in the alongwind direction.

The normalized autocorrelation function, $R(\tau)$, is

$$
R(\tau)=\frac{\int_{0}^{\infty} n S(n) F(n) \cos (2 \pi n \tau) d[\ln (n)]}{\int_{0}^{\infty} n S(n) F(n) d[\ln (n)]} .
$$

Taylor's hypothesis (Taylor 1938) states that in the direction of the mean wind, the spatial correlation $R(s)$ is equal to $R(\tau)$ provided that $\tau=s / U$ where $U$ is the mean wind speed and $s$ is the separation distance. That is,

$$
R(s)=R(\tau), \quad s=U \tau
$$

This simple model has many deficiencies. For example, it has been found that in the boundary layer the eddies travel slightly faster than the mean wind (see Mizuno and Panofsky 1975 or Powell and Elderkin 1974.) (This means that the value of $U$ applying is about 5 to $10 \%$ greater than the mean wind speed).

The subject of this report is how well these models apply when $n S(n)$ is given a specific form from the literature and when the specification of $F(n)$ is appropriate to the time scale of interest. Where these models are deficient, improved models or empirical adjustments to existing models are suggested. 


\subsection{THE SPECTRAL MODEL FOR THE NEUTRAL ATMOSPHERE}

In much wind engineering literature the assumption is made that because atmospheric stability approaches neutrality during high wind speeds, a spectral model for the neutral atmosphere is sufficient. Thereby, models for the unstable and stable atmospheres are excluded. In this report, both neutral and unstable atmospheric models are considered.

The spectral model for the neutral atmosphere used in this work is the Kaimal spectrum for neutral stability (Kaimal et al. 1972). The equation is given in dimensionless form for a dimensionless frequency,

$$
f=n z / U
$$

where $z$ is height above the ground, and $U$ is mean wind speed. Physically this reflects the fact that turbulence in the mean wind direction is scaled according to height, and theoretically the scale of turbulence is independent of the mean wind speed. Kaimal's equation for the neutral atmosphere is

$$
\frac{n S_{u}(n)}{u_{\star}^{2}}=\frac{105 f}{(1.0+33 f)^{5 / 3}}
$$

$u_{\star}$ is the friction velocity. It is presumed to apply through a layer where the mean wind speed $U(z)$ changes with height. For the neutrally stable atmosphere the relation between $u_{\star}$ and $U(z)$ is given by the logarithmic wind law,

$$
U \frac{u_{\star}}{U(z)}=\frac{0.4}{\ln \left(\frac{z}{z_{0}}\right)}
$$

where $z_{0}$ is the surface roughness length (see Panofsky and Dutton 1984 or Appendix A.) 
This form is recommended in preference to the form

$$
\begin{gathered}
\frac{n S_{u}(n)}{2}=\frac{0.164\left(f / f_{0}\right)}{\left[1.0+0.164\left(f / f_{0}\right)^{5 / 3}\right]} \\
f_{0}=0.0144
\end{gathered}
$$

that is frequently found in WT literature. This is actually Kaimal's spectrum for the stable atmosphere (Kaimal 1973) adapted to fit the neutral atmosphere by use of the value 0.0144. Frost et al. (1978) give $f_{0}$ values for all three components $(u, v, w)$ for this spectrum. However the variance requires some arbitrariness to evaluate it, see Section 2.3.1. Also in Section 4 it is found that in the minutes time frame integration of $(2.1-2)$ underestimates the rms. Because the Kaimal-frost spectrum (2.1-4) has even less energy at low frequencies when the two are forced to coincide in the high frequency range (where the modeling is more certain), integration of the Kaimal-Frost spectrum to produce an rms in the minutes time frame would increase the error. However the two spectra are not really far apart. If one assumes that the square root of the variance in Equation (2.1-4) is 2.3 times $u_{*}$, the comparison is as shown in Figure 2.1 .

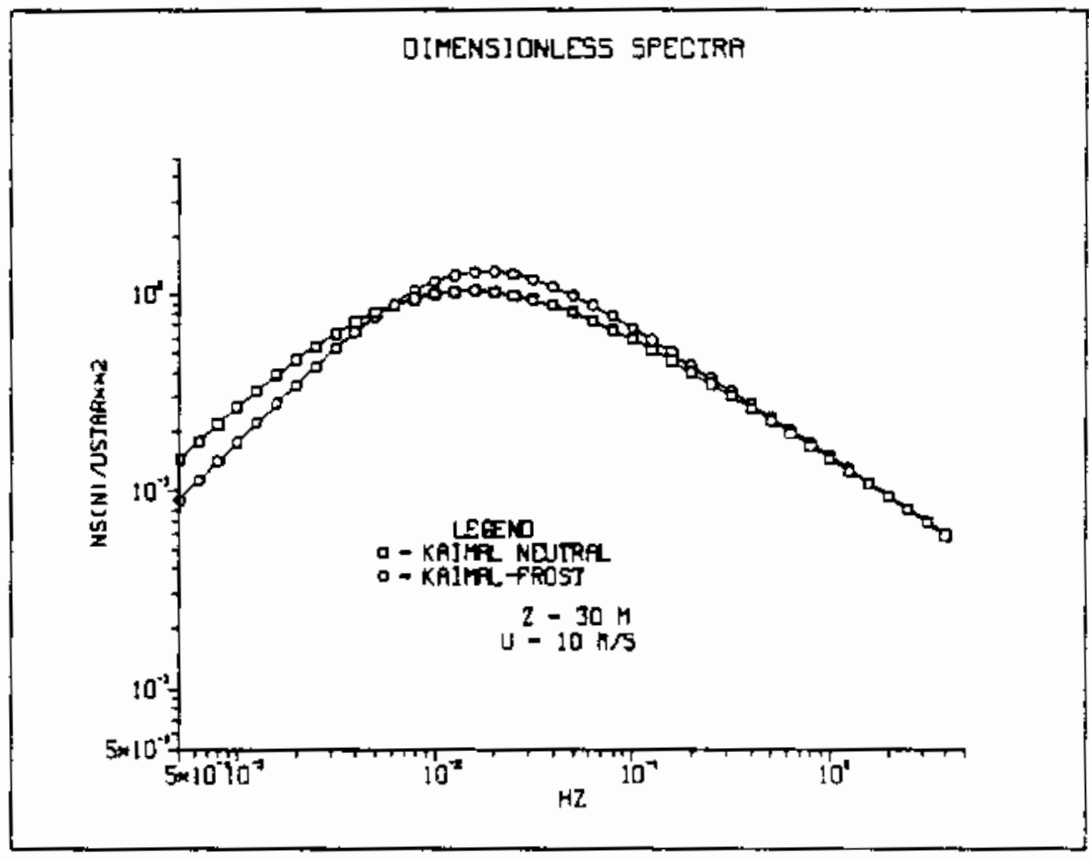

FIGURE 2.1. Comparison of Kaimal and Kaimal-Frost u Spectra for Neutral Stability 


\subsection{THE FILTER MODEL}

The same meteorological data were analyzed under five different bandpass filter conditions. If $u(t)$ is wind speed at time $t$, we apply the name undifferenced data, which are defined as

$$
u(\Delta t ; t)=u(t+\Delta t)-u(t)
$$

where $\Delta \tau$ is the differencing time. Undifferenced data were analyzed to quantify load-following requirements (see Chan, Powell et al. 1983). Undifferenced data are defined as $U(t)-\bar{U}$, where $\bar{U}$ is a long-term average. They were analyzed to quantify load-following requirements.

The band-pass filtering applied to the undifferenced data consists of low-pass and high-pass filtering operations defined as follows:

Low-pass filter: 1-min averaging

High-pass filter: Subtraction of a 30 -min running mean from the 1 -min averaged data.

Differencing intervais of $1,3,10$, and $30 \mathrm{~min}$ were used to evaluate load following requirements on each of those time scales. Differencing is modeled by a high-pass filter. Therefore four more filters are defined according to:

High-pass filters: Differencing $1-$ min averaged data at $1,3,10$, or $30 \mathrm{~min}$.

Specific mathematical forms of $F(n)$ are given in Appendix A, Section A.3.

\subsection{GENERAL COMMENTS ON THE SPECTRAL MOOEL}

Pursuit of the goals of wind energy production and distribution requires that meteorologists read engineering literature and that engineers read meteorological literature. In either case acquiring a basic understanding is difficult, and important contingencies and qualifying aspects may be missed. Accordingly the author makes some qualifying observations regarding meteorological turbulence spectra at this point. 


\subsubsection{Spectral Gap Hypothes is}

The engineer's confidence in understanding basic turbulence theory as it applies in the atmospheric boundary layer begins with the spectral gap hypothesis (see Van der Hoven 1957.). The author believes that the hypothesis is in some respects misleading.

The spectral hypothesis is illustrated in Figure 2.2 (Van der Hoven 1957). The author has added a dashed fine to the graph, and its explanation is given on the following page.

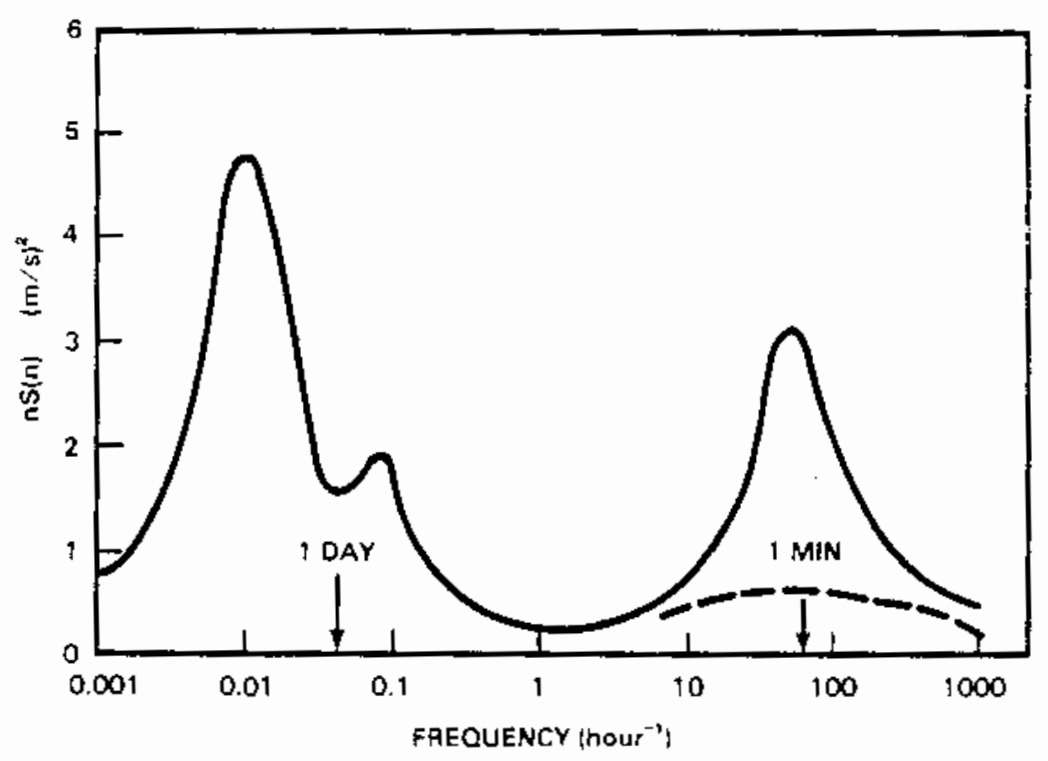

FIGURE 2.2. Reinterpretation of Spectral Gap 
This figure can be used to argue that there are two easily definable peaks of wind speed variation. The low-frequency peak is that of synoptic scale variation, and the higher frequency peak is that of turbulence. Therefore, there is a natural criterion for dividing the total wind into mean flow and variation about that mean flow. The graph shows that it is easy to compute turbulence variance by integrating under the high frequency hump.

The maximum turbulence value under the hump is $3(\mathrm{~m} / \mathrm{s})^{2}$. This value is anomalous and would, under most conditions, correspond to wind speeds approaching, if not exceeding, the cut-out speed of a WT. A more realistic level is indicated by the dashed line under the hump. This line was calculated as follows.

We assume that the Kaimal spectrum described by Equations (2.1-1), (2.1-2) and (2.1-3), is representative for the peak spectral value. The peak value in the dimensional arrangement is a function of mean wind speed and surface roughness. Let us assume a fajrly brisk operational speed of $9 \mathrm{~m} / \mathrm{s}$ for the wind at $10 \mathrm{~m}$. A typical value of $z_{0}$ for a rural setting is $0.1 \mathrm{~m}$. From Equation (2.1-3) we calculate a value of $0.78 \mathrm{~m} / \mathrm{s}$ for $u_{\star}$, or $0.61(\mathrm{~m} / \mathrm{s})^{2}$ for $\left(u^{*}\right)^{2}$. This yields a maximum value of less than $0.7(\mathrm{~m} / \mathrm{s})^{2}$ for $n S(n)$ instead of $3(\mathrm{~m} / \mathrm{s})^{2}$. This is the dashed line drawn across the original figure.

When the dashed line is substituted, a naturally defined frequency bandwidth for calculating turbulence variance is no longer present. Therefore, extrameteorological criteria must be imposed to caiculate a turbulence variance (or rms). For WT applications considered by Chan, Poweil, et al. (1983), the criterion is the frequency response of the utility's automatic generation control system. 


\subsubsection{On the Use of State-of-the-Art Spectra for the Alongwind Component of Turbulence}

The Van der Hoven spectrum is not generally integrated to calculate turbulence variances, or rms. Some qualifying observations should be made about the state-of-the-art u-component (aiongwind component) spectra that are so used. There are two types of spectra to be discussed: those that model the neutral atmosphere and those that mode? the unstable atmosphere.

\subsubsection{Neutral Atmosphere}

This spectrum (see Equation (2.1-2)) of one smooth curve may give the appearance of reflecting the same physics throughout its frequency range, or at least being usable with the same confidence throughout its frequency range. Actually nejther is true. The low- and high-frequency parts of this spectrum reflect very different physical phenomonena. The wind variation in the high-frequency part is three-dimensional turbulence, a dissipative process, for which the spectral level is well agreed upon as established by arguments involving dimensional analysis and the Kolmogoroff constant (see Kaima) et a]. 1972). The wind variation in the low-frequency part is quasi-horizontal motion that does not participate appreciably in energy dissipation and which is subject to other physical infiuences that are either not as well formulated or difficult to describe, or both. For example, one of these influences is surface roughness and terrain characteristics at some distance upwind of the site. Panofsky (1973) has noted that alt studies of the low-frequency portions of u spectra come up with different results. Different upwind terrain is one reason for this. Others are different degrees of success in finding data representing stationary periods and use of different detrending artifices on these data, i.e., the best fitting linear or second-order polynomial or some kind of end tapering. 
Since wind turbines operate when the wind is in the operational range, whether the atmosphere is stationary or not, the question arises regarding just how much bias there is when typical wind variation in the minutes time frame is assessed by a model allowing for minimum wind variation in some of that frequency range.

\subsubsection{Unstable Atmosphere}

The second problem is with unstable conditions. As the solar angle with the horizon increases and atmospheric stability under a clear sky changes from stable to neutral to unstable, there is a quasi-discontinuous jump in low-frequency energy as the stability changes from neutral to unstable. The accepted model turbuience spectra for unstable conditions are those of Højstrup (1981; see Appendix A). They require additional meteorological parameters that engineers are generally not familiar with. According to these parameters, low-frequency energy increases as instability increases and as the depth of the convective layer increases. Using the Hojstrup equation it was estimated that typically the rms of turbulence in the minutes time frame according to the unstable model is about 1.7 that predicted by the neutral model (Equation 2.1-2). Also turbulence rms values calculated directly from data analysis for unstable conditions were compared to estimates calcuiated by integrating the Højstrup spectrum. As shown in Section 4, this comparison was generally good.

The Højstrup model and all parameterizations are given in Appendix A.

\subsubsection{Stable Atmosphere}

The rms model for the neutral atmosphere is regarded as a conservative upper-bound model applicable to rms of the stable atmosphere. Therefore, the spectral model for a stable atmosphere is not considered in this work. 



\subsection{DATA ANALYZED AND SITE CHARACTERISTICS}

Wind observations analyzed in this paper originated from four sites:

1) the Oklahoma PAM Network

2) the Clayton, New Mexico, vertical plane array

3) the WKY tower, Oklahoma City

4) the BPA and PNL towers at Goodnoe Hills, Washington.

\subsection{SITE AND INSTRUMENTAT ION CHARACTERISTICS}

\subsubsection{Oklahoma PAM Network}

Data from the PAM network were taken simultaneously from an array of 27 individual sites in rural west-central Oklahoma. These observation stations were laid out roughly in the shape of a diamond, and the characteristic separation distance between adjacent sites is $16 \mathrm{~km}$ (10 mi). Each site has one 4-m tower at which height measurements were taken. These data are used for estimating the spatial cross correlations at the $16 \mathrm{~km}$ separation distance.

\subsubsection{Clayton, New Mexico}

The Clayton data were taken from the $60-m$ and $30-m$ levels of the central tower of the Clayton vertical $\mathrm{pl}$ ane array. The center tower is $78 \mathrm{~m} \mathrm{SSW}$ of the MOO-OA wind turbine. Since only the southwesterly and westerly directions were free from obstruction by either the other towers of the array or by the MOO-OA wind turbine, the analysis is restricted to winds from that sector. In the immediate area the terrain is flat and a roughness length of about $0.5 \mathrm{~cm}$ is appropriate for the sparse ground cover over short grass (Chan, Powell et al. 1983). The Clayton data are analyzed to estimate bias in the spectral model for rms values only. 


\section{1 .3 WKY Tower}

The WKY TV tower is located about $10 \mathrm{~km}$ NNE of downtown Oklahoma City (see Sanders and Weber 1970) in an area that was relatively undeveloped within a $3-\mathrm{km}$ radius. The tower is equipped with wind and temperature sensors at seven heights up to $445 \mathrm{~m}$ above ground. The data analyzed for this report were taken from the $26-$ and $45-\mathrm{m}$ levels.

Sanders and Weber give roughness lengths varying from 0.2 to $14 \mathrm{~cm}$ that apply when the wind is from different directions. These data were used as were the clayton data to estimate bias in the spectral model for the rms.

\section{1 .4 Goodnoe Hills}

The Goodnoe Hills WT site is located 15 miles ESE of Goldendale, Washington, on a $800-m$ ridge overlooking the CoIumbia River (see Gordon 1982). The immediate area is grassy and somewhat rolling with patches of woods and a ravine intruding the area. The data were from the 61-m level of the BPA (Bonneville Power Administration) and PNL towers, which are separated by $675 \mathrm{~m}$ in a direction of $269^{\circ}$ (east-west). The base of the PNL tower is $14 \mathrm{~m}$ higher than the base of the BPA tower. These data were used to calculate the spatial cross-correlation at the available separation distance.

\subsection{DATA CHARACTERISTICS}

Almost all of the data segements analyzed were of 4 hours' length, starting at a time when the wind at WT hub height was within operating range for WTs, which was taken to be $6 \mathrm{~m} / \mathrm{s}$ or greater. None of the data were taken during times when the wind speed exceeded a typical cut-out speed, such as $20 \mathrm{~m} / \mathrm{s}$. One of the principal objectives of this paper was to analyze data taken at such randomly chosen times rather than times of maximum stationarity. Therefore all runs were used if the wind speed maintained itself at not much less than $6 \mathrm{~m} / \mathrm{s}$ through the $4-\mathrm{hr}$ period regardless of how non-stationary the wind was otherwise. However, no periods marked by storms or frontal discontinuities were analyzed. 


\subsubsection{OKT ahoma PAM Network}

Four 4-hr segments of data from this array were analyzed. The data were all 1-min block averages. In each case data from five locations that formed an L-shape were analyzed in such a manner that as nearly as possible one arm of the $L$ was in the alongwind direction and the other arm in the crosswind direction. The separation distances between adjacent locations were about $16 \mathrm{~km}$.

The starting times are given in Table 3.1.

TABLE 3.1. Starting Times, Local Time, PAM Data

$$
\begin{array}{lll}
0000 & \text { May 02, } & 1979 \\
1330 & \text { May 02, } 1979 \\
0900 & \text { May 18, } & 1979 \\
1421 & \text { May 20, } & 1979
\end{array}
$$

\subsubsection{Clayton, New Mexico}

Eleven 4-hr segments of data from each of the 60 - and $30-\mathrm{m}$ heights of

\begin{tabular}{|c|c|c|}
\hline Starting Time & $\begin{array}{l}\text { Speed, } \\
(\mathrm{m} / \mathrm{s})\end{array}$ & $\begin{array}{l}\text { Direction } \\
\text { at } 30 \mathrm{~m} \text { (degrees) }\end{array}$ \\
\hline $\begin{array}{l}0345 \text { August } 09,1981 \\
0734 \text { August 13, } 1981 \\
0934 \text { August 13, } 1981 \\
1134 \text { August 13, } 1981 \\
1334 \text { August 13, } 1981 \\
1534 \text { August 13, } 1981 \\
1734 \text { August 13, } 1981\end{array}$ & $\begin{array}{l}5.6 \\
8.7 \\
9.7 \\
8.2 \\
7.8 \\
6.8 \\
6.7\end{array}$ & $\begin{array}{l}278 \\
223 \\
217 \\
212 \\
206 \\
199 \\
201\end{array}$ \\
\hline $\begin{array}{l}0334 \text { August } 14,1981 \\
0534 \text { August 14, } 1981\end{array}$ & $\begin{array}{l}6.3 \\
6.3\end{array}$ & $\begin{array}{l}252 \\
252\end{array}$ \\
\hline $\begin{array}{l}2024 \text { December 04, } 1981 \\
2224 \text { December 04, } 1981\end{array}$ & $\begin{array}{l}6.5 \\
7.5\end{array}$ & $\begin{array}{l}248 \\
246\end{array}$ \\
\hline
\end{tabular}
the tower were analyzed. The starting times and average wind directions at the $30-m$ level are given in Table 3.2 .

TABLE 3.2. Starting Times, Wind Speed and Direction, Clayton Data 
All these runs were modeled as neutral stability. During the morning hours of August 13 when unstable conditions normally prevail, the weather was cloudy and the dew point temperature was within a few degrees of the actual temperature, due to the presence of moist air originating over the Gulf of Mexico. No rain or thunderstorms were reported on the weather map at that time.

Upon re-examination of this work, it appeared that the runs starting at 1134 and 1334 should have been classified as unstable because of clearing skies. Accordingly, these data were deleted from the sample of data analyzed as neutral for this report.

\subsubsection{WKY Tower, OK lahoma}

Thirty-five runs of these data were analyzed at the $45-\mathrm{m}$ and $26-\mathrm{m}$ levels. Twenty-three of these were analyzed as unstable; twelve were analyzed as neutrat. Analysis of these data required using the roughness lengths given by Sanders and Weber (1970) for different directions. Also values of the Monin-Obukhov length $-L$ and the depth of the convective Tayer $z_{i}$ (see Appendix A) had to be assumed for each test in the unstable atmosphere. Speed and direction are for the 45-m level (see Table 3.3).

\subsubsection{Goodnoe Hills}

These data were used only for analysis of the spatial correlation. They were not used to estimate bias of the rms because no estimated roughness length was available for this complex terrain site at the time the analys is was made.

The data of some of the tests are 2-min averages. The division of the 44 runs between 1 - and $2-$ min averages is given below.

The wind directions vary little from that of the Columbia River. There are two reasons for this. First, the prevailing wind direction at this site is the direction of the river; and second, a wake effect from one of the turbines marred the data at one of the recording sites during those few tests when the wind direction was roughly perpendicular to that of the 
TABLE 3.3. Starting Times, Wind Speed and Direction and 0ther Parameters, WKY Tower Data

\section{UNSTABLE CONDITIONS}

\begin{tabular}{|c|c|c|c|c|c|}
\hline Starting Time & $\begin{array}{l}\text { Speed } \\
(\mathrm{m} / \mathrm{s}) \\
\end{array}$ & $\begin{array}{l}\text { Direction } \\
\text { (degrees) }\end{array}$ & $\begin{array}{r}z_{0} \\
(\mathrm{Cr}) \\
\end{array}$ & $\begin{array}{l}-L \\
(m)\end{array}$ & $\begin{array}{r}z i \\
(\mathrm{~km}) \\
\end{array}$ \\
\hline $\begin{array}{l}08001 / 18 / 77 \\
1000 \\
1200 \\
1400\end{array}$ & $\begin{array}{r}11.0 \\
9.8 \\
8.1 \\
7.1\end{array}$ & $\begin{array}{l}320 \\
324 \\
331 \\
341\end{array}$ & $\begin{array}{l}1 \\
5 \\
5 \\
5\end{array}$ & $\begin{array}{r}100 \\
50 \\
70 \\
50\end{array}$ & $\begin{array}{l}1.2 \\
1.2 \\
1.2 \\
1.2\end{array}$ \\
\hline $\begin{array}{ll}1200 & 7 / 3 / 77 \\
1200 & 7 / 4 / 77 \\
1200 & 7 / 5 / 77 \\
1200 & 7 / 6 / 77\end{array}$ & $\begin{array}{l}8.3 \\
7.3 \\
7.6 \\
6.5\end{array}$ & $\begin{array}{l}182 \\
182 \\
182 \\
184\end{array}$ & $\begin{array}{l}6 \\
6 \\
6 \\
6\end{array}$ & $\begin{array}{l}45 \\
35 \\
40 \\
30\end{array}$ & $\begin{array}{l}1.8 \\
1.8 \\
1.8 \\
1.8\end{array}$ \\
\hline $\begin{array}{l}09008 / 7 / 77 \\
1100 \\
1300 \\
1500 \\
09008 / 9 / 77 \\
1100 \\
1300 \\
1500 \\
09008 / 27 / 77 \\
1100 \\
1300\end{array}$ & $\begin{array}{r}7.3 \\
6.8 \\
6.8 \\
7.2 \\
8.0 \\
7.3 \\
7.3 \\
7.7 \\
11.5 \\
11.7 \\
11.8\end{array}$ & $\begin{array}{l}208 \\
204 \\
189 \\
178 \\
209 \\
200 \\
188 \\
182 \\
185 \\
179 \\
173\end{array}$ & $\begin{array}{r}2 \\
2 \\
4 \\
8 \\
2 \\
2 \\
5 \\
6 \\
6 \\
8 \\
10\end{array}$ & $\begin{array}{r}35 \\
35 \\
35 \\
40 \\
45 \\
35 \\
35 \\
40 \\
100 \\
100 \\
100\end{array}$ & $\begin{array}{l}1.2 \\
1.5 \\
1.8 \\
1.5 \\
1.0 \\
1.5 \\
1.8 \\
1.5 \\
1.0 \\
1.5 \\
1.8\end{array}$ \\
\hline $\begin{array}{l}080012 / 9 / 76 \\
1000 \\
1200 \\
1400\end{array}$ & $\begin{array}{l}13.6 \\
13.6 \\
13.3 \\
11.4\end{array}$ & $\begin{array}{l}189 \\
189 \\
190 \\
186\end{array}$ & $\begin{array}{l}3 \\
3 \\
3 \\
4\end{array}$ & $\begin{array}{l}150 \\
150 \\
150 \\
150\end{array}$ & $\begin{array}{l}1.0 \\
1.0 \\
1.2 \\
1.2\end{array}$ \\
\hline
\end{tabular}

NEUTRAL CONDITIONS

$00001 / 13 / 77$

Speed

$\frac{\begin{array}{l}\text { Direction } \\ \text { (degrees) }\end{array}}{174}$

0400

10.5

7.8

9.1

$04001 / 18 / 77$

9.3

10.0

$z_{0}$

0600

9.4

$0000 \quad 12 / 9 / 76$

9.2

0400

10.7

0600

12.6

11.0

10.8

1800

10.6

174

180

335

323

(cm)

10

10

7

10

10

176

182

187

180

178

181 
river. The numerical value of the direction at the PNL tower reads dependably about $15^{\circ}$ greater than the reading at the BPA tower. This is thought to be correct, reflecting true curvature of the wind at this site. The directions given are the average of the values given for the two sites. These data are given in Table 3.4.

A weak occluded front passed through the Goodnoe Hills area at about 0600 PST on September 1, 1981. The occluded front, which is typical of fronts that pass over the Pacific Northwest, did not change the wind direction as a genuine cold front does, and as is characteristically observed over the middle-west. In fact the front increased rather than decreased the stationarity of the winds. 
TABLE 3.4. Starting Times, Wind Speed and Direction for Goodnoe Hills Data

TWO-MINUTE AVERAGING

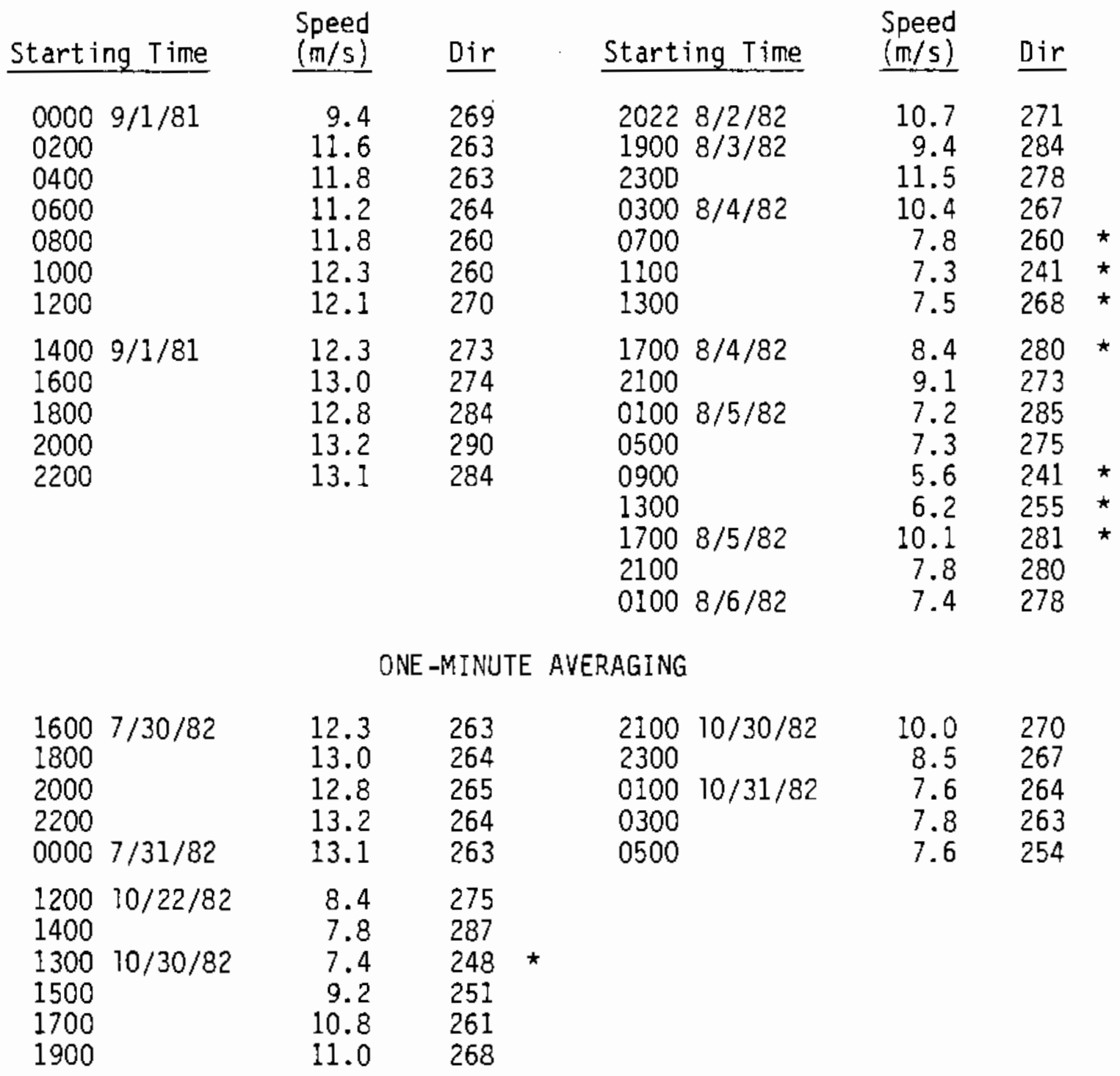

NOTE: The symbol * indicates an unstable case. 
? : 


\subsection{RESULTS OF DATA ANALYSIS}

\subsection{RMS VALUES AT A SINGLE SITE}

This analysis is based on three sets of data.

1) Clayton 60 and $30 \mathrm{~m}$ - neutral stability

2) WKY 45 and $26 \mathrm{~m}$ - neutral stability

3) WKY 45 and $26 m$ - unstable.

For each data segment analyzed, rms values were calculated for each set of the five filter versions defined in Section 2.2. The final evaluation consisted of defining a bias ratio RB according to:

$$
R B=(\text { observed rms }) /(\text { predicted rms }) .
$$

The predicted rms will be for either neutral or unstable conditions depending on the stability prevailing at the time of the run. The prediction for the neutral atmosphere is made by evaluating Equation (2.0-3) using the spectral model of Equation $(2.1-2)$, with $u_{\star}$ evaluated from Equation (2.1-3), with applicable values of $U(z)$ and $z_{0}$. The prediction for the unstable atmosphere is made by evaluating Equation (A-6), Appendix $A$ with all necessary associated equations and parameterization.

The tables below do not include a ratio of rms predicted by the unstable model to that predicted by the neutral model. Of course this ratio depends on assumed values of $z_{j}$ and $-L$. For most commonly encountered values of $z_{j}$ and $-L, 1.7$ is a representative value (see Appendix A).

\subsubsection{The Unstable Atmosphere}

First of all, for the unstable atmosphere, no significant bias is shown for the model for any of the data species (see Table 4.1). 
TABLE 4.1. RB for Unstable Conditions, WKY Tower.

\begin{tabular}{|c|c|c|c|c|c|}
\hline \multirow[b]{2}{*}{ Data Type } & \multirow{2}{*}{ Undif. } & \multicolumn{4}{|c|}{ Differenced } \\
\hline & & min & $3 \min$ & $10 \mathrm{~min}$ & $30 \mathrm{~min}$ \\
\hline $\begin{array}{l}R B(z=45 \mathrm{~m}) \\
R B(z=26 \mathrm{~m})\end{array}$ & $\begin{array}{l}1.01 \\
1.07\end{array}$ & $\begin{array}{l}0.93 \\
1.01\end{array}$ & $\begin{array}{l}0.97 \\
1.03\end{array}$ & $\begin{array}{l}1.03 \\
1.09\end{array}$ & $\begin{array}{l}1.09 \\
1.15\end{array}$ \\
\hline
\end{tabular}

The denominator of RB, Equation (4.1-1), is the rms predicted by the Højstrup model. There are two main points.

1) Integration of the $H \bowtie j s t r u p$ equations appears to be a good predictor of turbulence rms in the minutes time frame.

2) These RB values would be larger by a factor of about 1.7 if the denominator had been calculated using the neutral model spectrum, Equation 2.1-2.

\subsubsection{The Neutral Atmosphere}

The ratios of observed-to-predicted values for neutral stability are given in Tables 4.2 and 4.3 for two sites: WKY tower and Clayton.

TABLE 4.2. RB for Neutral Conditions, WKY Tower

\begin{tabular}{|c|c|c|c|c|c|}
\hline \multirow[b]{2}{*}{ Data Type } & \multirow[b]{2}{*}{ Und if. } & \multicolumn{4}{|c|}{ Differenced } \\
\hline & & $I \min$ & $3 \min$ & $10 \mathrm{~min}$ & $30 \mathrm{~min}$ \\
\hline $\begin{array}{l}R B(z=45 \mathrm{~m}) \\
R B(z=26 \mathrm{~m})\end{array}$ & $\begin{array}{l}1.11 \\
1.36\end{array}$ & $\begin{array}{l}1.17 \\
1.38\end{array}$ & $\begin{array}{l}1.12 \\
1.35\end{array}$ & $\begin{array}{l}1.18 \\
1.42\end{array}$ & $\begin{array}{l}1.41 \\
1.64\end{array}$ \\
\hline
\end{tabular}

TABLE 4.3. RB for Neutral Conditions, Clayton.

\begin{tabular}{|c|c|c|c|c|c|}
\hline \multirow[b]{2}{*}{ Data Type } & \multirow[b]{2}{*}{ Und if. } & \multicolumn{4}{|c|}{ Differenced } \\
\hline & & $1 \mathrm{~min}$ & $3 \min$ & $10 \min$ & $30 \mathrm{~min}$ \\
\hline $\begin{array}{l}\text { RB }(z=60 \mathrm{~m}) \\
R B(z=30 \mathrm{~m})\end{array}$ & $\begin{array}{l}1.10 \\
1.29\end{array}$ & $\begin{array}{l}.84 \\
.96\end{array}$ & $\begin{array}{r}.93 \\
1.10\end{array}$ & $\begin{array}{l}1.27 \\
1.52\end{array}$ & $\begin{array}{l}1.60 \\
1.93\end{array}$ \\
\hline
\end{tabular}


The main points are:

- The bias decreases with height.

- The bias increases with increase of differencing interval.

In the Clayton analysis the increase of bias with differencing interval is considerably greater than in the WKY anaTysis. One possible explanation is the variation of surface roughness at different distances from the tower at each site. For the tests at Clayton there is a 1 arge step increase of roughness at a distance of $1 / 2 \mathrm{~km}$ upwind. For several of the tests at the WKY tower, with south wind, there was markedly greater roughness in the vicinity of the tower than farther away.

According to Panofsky et al. (1982), low-frequency energy measured at a site will be more or less according to whether the roughness in the upwind direction is generally greater or less than that at the site. Therefore, if the spectral model were unbiased, $(R B=1.0)$, it would appear to underpredict or overpredict according to whether the roughness in the upwind direction is generally greater or less than that at the site. The difference in RB for the two site analyses reflects this criterion, while showing underprediction by the model in both cases.

If one were to contest the results of Tables 4.2 and 4.3 by saying that some of the data analyzed as neutral should have been analyzed as unstable, then it follows that the need for the unstable model is all the greater.

Rough interpolations or extrapolations of these results to other heights will most probably hold, but not extrapolations to markedly different filter conditions. 


\subsection{ZERO-TIME-LAG SPATIAL CORRELATIONS}

\subsubsection{Inter-cluster Separation Oistance}

Four data segments from the OkTahoma PAM network were anaTyzed. For each run five stations were chosen such that their locations formed an $L$ shape with one arm approximately in the mean win direction and the other arm perpendicular to the first. Each leg of the $L$ was about $32 \mathrm{~km}$.

No significant spatial correlation at the separation distance of $16 \mathrm{~km}$ was found consistently in any of the runs. More specifically the spatial correlations for the differenced data were $-0.01,0.03$, and 0.14 for differencing intervais of 3,10 , and 30 minutes respectively. For the undifferenced data average spatial correlation was 0.008 , or effectively zero.

This analysis may be adversely affected by the fact, mentioned in section 3.1.1, that the data were taken at a height of $4 \mathrm{~m}$. At a typical WT hub height, such as $60 \mathrm{~m}$, there may be a significant correlation in random non-event turbulence that does not exist in winds at a height of $4 \mathrm{~m}$. Oata appropriate for the analys is of this report has not been found in sufficient quantity.

\subsubsection{Inter-WT Separation Distance}

Spatial correlations were calculated from the Goodnoe Hills data for the one available distance, $674 \mathrm{~m}$, (see Section 3) and at one height, $60 \mathrm{~m}$. Altogether 44 runs of Goodnoe Hills data were analyzed. The runs were as follows:

$\begin{array}{lrrr}\text { September } & 1981 & 12 \text { runs - } 2 \text { minute averages } \\ \text { July } & 1982 & 5 \text { runs - } 1 \text { minute averages } \\ \text { August } & 1982 & 16 \text { runs - } 2 \text { minute averages } \\ \text { October } & 198211 \text { runs - } 1 \text { minute averages. }\end{array}$


The average values of all these correlations vary from one set to another. A complete table (Table 4.4) of the averages is given below. The heading $U 30$ refers to the undifferenced data. The other headings refer to the differencing interval of the differenced data.

TABLE 4.4. Average Value of Spatial Correlations at a Separation Distance of $674 \mathrm{~m}$ and a Height of $60 \mathrm{~m}$, Goodnoe Hills

\begin{tabular}{|c|c|c|c|c|c|c|}
\hline \multirow[b]{2}{*}{ Month/Year } & & \multirow[b]{2}{*}{$43 D^{(a)}$} & \multicolumn{4}{|c|}{ Differenced Data } \\
\hline & & & $1 \mathrm{~min}$ & $3 \min$ & $10 \mathrm{~min}$ & $30 \mathrm{~min}$ \\
\hline $\begin{array}{l}\text { eptember } \\
\text { dly } \\
\text { ugust } \\
\text { ctober }\end{array}$ & $\begin{array}{l}1981 \\
1982 \\
1982 \\
1982\end{array}$ & $\begin{array}{l}0.509 \\
0.218 \\
0.348 \\
0.298\end{array}$ & -.083 & .152 & $\begin{array}{l}0.765 \\
0.392 \\
0.376 \\
0.430\end{array}$ & $\begin{array}{l}0.826 \\
0.621 \\
0.438 \\
0.620\end{array}$ \\
\hline
\end{tabular}

(a) Undifferenced data

The cross correlations are shown as a function of wind direction in the three figures following, Figures $4.1,4.2$ and 4.3 .

Little can be done from these data to exhibit the spatial correlation as a function of wind direction since only three of the 44 runs occurred when the average wind direction deviated from the tower line direction by more than $20^{\circ}$. There are two reasons for the preference for the narrow directional sector. One is the natural greater frequency of wind in the direction parailel to the Columbia River and the other is the fact that the data were rendered unsuitable by tower shadow, or wake effect, when the direction was perpendicular to the line between the BPA and PNL towers.

No differences in correlations could be attributed with certainty to the difference between neutral and unstable conditions. 


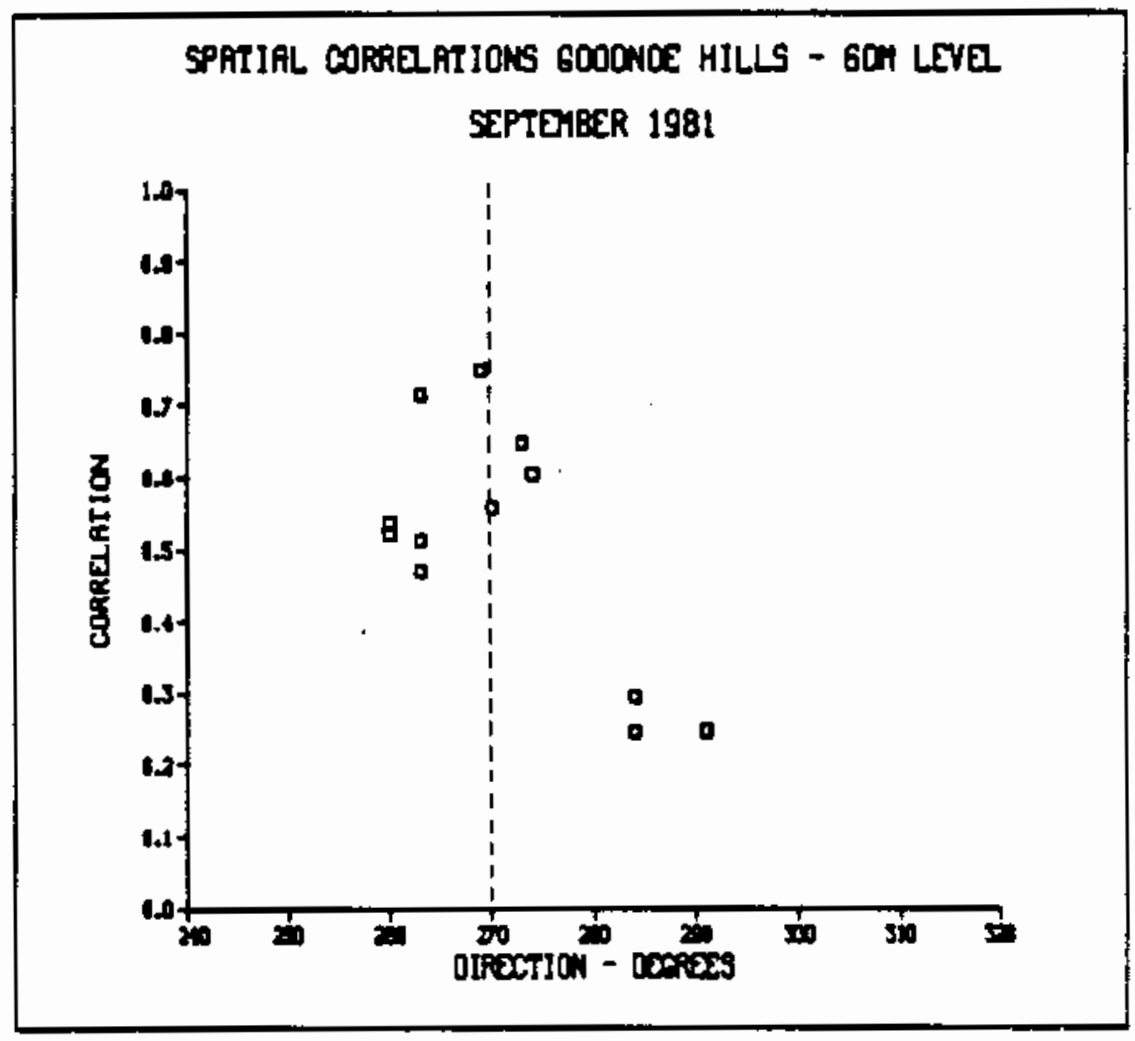

FIGURE 4.1. Spatial Correlation, Goodnoe Hills, September 1981 (The dashed line indicates the direction of the line between the towers.)

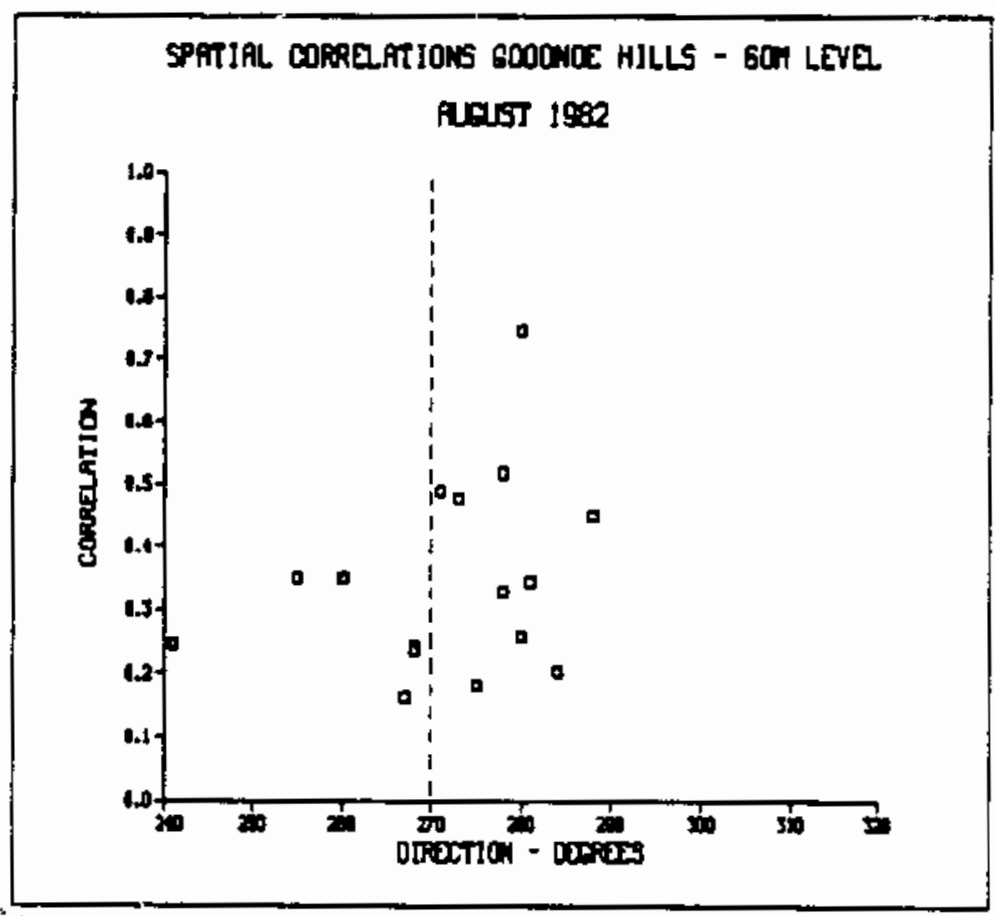

FIGURE 4.2. Spatial Correlation, Goodnoe Hills, August 1982 


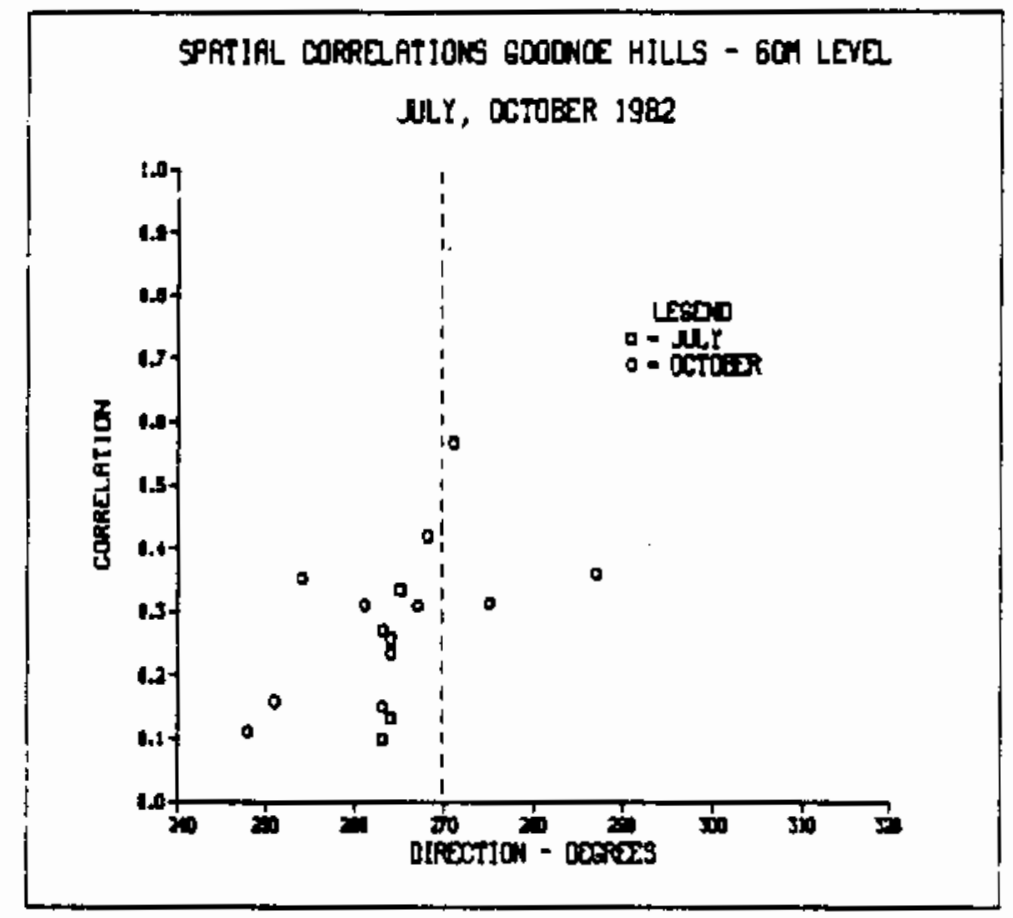

FIGURE 4.3. Spatial Correlation, Goodnoe Hilis, July October 1982

Ratios were computed between correlation lengths estimated from the correlations for undifferenced data in Table 4.4 and estimated using the spectral model and Taylor's hypothesis, Equations (2.0-4) and (2.0-5), with the Kaimal neutral spectum of Equation (2.1-2) and monthly averages of the mean wind speeds in Table 3.4. Exponential shape was assumed for the spatial correlation function. Therefore the correlation length $L_{C}$ is given by

$$
\begin{aligned}
& p=\exp \left(-s / L_{C}\right) \\
& \text { or } L_{C}=-s / \ln (p)
\end{aligned}
$$


where $p$ is the measured correlation, and $s$ is the separation distance of $674 \mathrm{~m}$. If we use the term $L_{c}$ (measured) and $L_{c}$ (modeled) to indicate $L_{c}$ derived from Equation (4.2-1) and $L_{c}$ derived from Equations (2.0-4), (2.0-5) and $(2.1-2)$, respectively, the ratio of these quantities

$$
R L_{C}=L_{C} \text { (modeled) } / L_{C} \text { (measured) }
$$

is of critical interest in evaluating such a model. This is because $L_{c}$ is the only parameter used to describe the correlation when the exponential assumption is used. Such ratios for the four monthly data sets are given in Table 4.5 .

TABLE 4.5 Spatial Correlation Lengths and Ratio Between Those Modeled by Spectrai Means and by Exponential Assumption

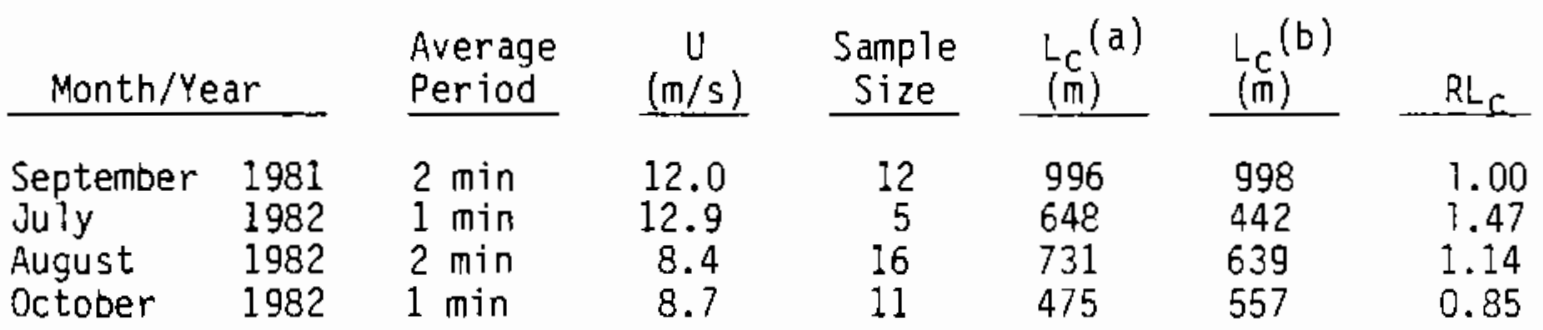

(a) modeled

(b) measured

There are several observations to make from this table. First, from inspection of the spectral model, we should expect $L_{c}$ (modeled) to increase with mean wind speed and with the averaging period applied to the data. This is clearly the case. The two values of $L_{C}$ (modeled) for 2 -min averaged data are greater than the two values for 1-min averaged data. Also when the averaging period is the same, the mean wind speeds are quite different, and the difference correlates with $L_{c}$ (modeled). Also from the spectral model, we see that $L_{c}$ depends on height, which was constant in the Goodnoe Hills data anaiyzed for this report. 
Second, the average value of $R L_{c}$ (when each monthly value is weighted by the size of the monthly sample) is 1.07 . This ratio should be regarded as satisfactory for virtually any comparison of observed to modeled results of a meteorological nature, owing to questions that always attend parameterization of meteorological models for non-ideal situations, such as complex terrain and nonstationary flow.

Third, the deviation of $\mathrm{RL}_{\mathrm{c}}$ from month to month in this small sample is great enough to reduce statistical confidence in a quoted average value. More data of this type should be analyzed. 



\subsection{RECOMMENDATIONS}

Because required amounts of reserve and load-following ability are quite sensitive to the zero-time-lag correlation between turbines, a much more definitive statement needs to be made regarding spatial correlations than that given in this report. The following steps are recommended at this time:

1) analysis of more Goodnoe Hills data with the wind in the tower line direction to resolve questions about applicability of correlation mode 1

2) analysis of Goodnoe Hills data with the wind direction perpendicular to the tower line

3) an extended search for other pertinent published results and for additional data to be analyzed.

As a result of these steps, we should know whether or not correlation modeling $c$ an be done with sufficient precision to justify recommending special new measurements to be undertaken for the purpose. We would also have an opinion on how representative such results would be when applied to other locations.

Comments from reviewers also indicate that the levels of turbulence and correlation exhibited in this report are not sufficient to be of concern in relation to reserve and load-following requirements. Also it has been recommended that the data be reanalyzed using filters that favor the following two time frames:

- 1 to 10 minutes, which is important to utility operators of steam units,

- 10 minutes to 60 minutes, which is of importance to systems operations. 


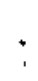




\subsection{REFERENCES}

Bendat, J. S. and A. G. Piersol. 1971. Random Data: Analysis and Measurement Procedures. Wiley-Interscience, New York, New York.

Chan, S. M., D. Curtice and S. K. Chang. 1983. Methods for Wind Turbine Dynamics Analysis. Report AP-3259. Prepared by Systems Control, InC., Palo Alto, CA 94304 for Electric Power Research Institute, Palo Alto, California.

Chan, S. M., D. C. Powell, M. Yoshimura and D. Curtice. 1983. "Dperations Requirements of Utilities with Wind Power Generation." IEEE Transactions on Power Apparatus and Systems. PAS-102(9):2850-2861.

Conne 11, J. R. 1981. The Spectrum of Wind Speed Fluctuations Encountered by a Rotating Blade of a Wind Energy Conversion System: Observations and Theory. PNL-4083. Available from National Technical Information Service, springfield, Virginia.

Couninan, J. 1975. "Adiabatic Atmospheric Boundary Layers: A Review and Analys is of Data From the Period 1880-1972." Atmos. Environ. 9:888.

Frost, W. B., H. Long and R. E. Turner. 1978. Engineering Handbook on the Atmospheric Environmental Guidelines for Use in Wind Turbine Generator Development. NASA Technical Paper 1359. National Aeronautics and Space Administration, Washington, D.C.

Garrett, J. R. 1980. "Surface Influence Upon Vertical Profiles in the Atmospheric Near-Surface Layer." Quar. J. Royal Met. Soc. 106:803-819.

Gordon, L. H. 1982. MOD-2 Wind Turbine System Cluster Research Test Program. Volume I, Initiai PTan. DOE/NASAT20305-8, U.S. Department of Energy, Conservation and Renewable Energy Wind Technology Division, Washington D.C.

Højstrup, J. 1981. "A Simple Model for the Adjustment of Velocity Spectra in Unstable Conditions Downstream of an Abrupt Change in Roughness and Heat Flux." Boundary-Layer Met. 21:341-356.

Holzworth, G. C. 1972. Mixing Heights, Wind Speeds, and Potential for Urban Air Pollution Throughout the Continguous United States. Environmental Protection Agency, Office of Air Programs, Research Triangle Park, North Carolina.

Izumi, Y., ed. 1971. "Kansas 1968 Fjeld Program Data Report." AFCRL-72-0041. In Environmental Research Papers, No. 379. Air Force Cambridge Research Laboratories, Cambridge, Massachusetts. 
Kaima1, J. C., J. C. Wyngaard, Y. Izumi and 0. R. Cote. 1972. "Spectral Characteristics of Surface Layer Turbulence." Quar. J. Royal Met. Soc. 98:563-589.

Kaimal, J. C. 1973. "TurbuTence Spectra, Length Scales, and Structure Parameters in the Stable Surface Layer." J. of Atmos. Sci. 35:18-24.

Lee, S. T, and Z. A. Yamayee. 1981. "Load-Following and Spinning-Reserve. Penalties for Intermittent Generation." IEEE Transactions on Power Apparatus and Systems. PAS-100(3):1203-1211.

Leslie, D. S. and A. W. Weber. 1970. Evaluation of Roughness Lengths at the NSSL-WKY Meteorological Tower. Technica! Memorandum NSSL 47, National Severe Storms Laboratory, Norman, Oklahoma. Available from National Technical Information Service, Springfield, Virginia.

Mizuno, T. and H. A. Panofsky. 1975. "The Validity of Taylor's Hypothesis in the Atmospheric Surface Layer." Boundary-Layer Met. 9:375-380.

Panofsky, H. A. 1973. "The Boundary Layer Above 30-m." Boundary-Layer Met. $4: 251-264$.

Panofsky, H. A., D. Larko, R. Lipschutz, G. Stone, E. F. Bradley, A. J. Bowen and J. Hojstrup. 1982. "Spectra of Velocity Components Over Complex Terrain." Quar. $J$ of the Royal Met. Soc. 108:215-230.

Panofsky, H. A. and J. Dutton. 1984. Atmospheric Turbulence. WileyInterscience, New York.

Paulson, C. A. 1970. "The Mathematical Representation of Wind Speed and Temperature in the Unstable Atmospheric Surface Layer." J. of App?. Met. 9:857-861.

Powe 17, D. C. and J. R. Conne 11. 1980. Definition of Gust Model Concepts and Review of Gust Mode 1s. PNL-3138, Pacific Northwest Laboratory, Richland, WA 99352. Availabie from National Technical Information Service. Springfield, Virginia.

Powei1, D. C. and C. E. Elderkin. 1974. "An Investigation of the Application of Taylor's Hypothesis to Atmospheric Boundary Layer Turbulence." $\mathrm{J}$. of the Atmos. Sci. 31:990-1002.

Sanders, L. O. and A. H. Heber. 1970. Evaluation of Roughness Lengths at the NSSL-WKY Meteorological Tower. Technical Memorandum, NSSL 47, National Severe Storms Laboratory, Norman, Oklahoma. Available from National Technical Information Service, Springfield, Virginia.

Taylor, G. I. 1938. "The Spectrum of Turbulence." Proc. Roy. Soc. London, $A(165): 476-484$.

Van der Hoven, I. 1957. "Power Spectrum of Horizontal Wind Speed in the Frequency from 0.0007 to 900 Cycles per Hour." J. Met. 14:160. 
APPENDIX A

MODELS OF FILTERED TURBULENCE FOR THE NEUTRAL AND

UNSTABLE BOUNDARY LAYERS 


\section{APPENDIX A}

The wind turbine layer in this report is assumed to be the height range over which the nacelle of a WT may be located when the wind turbine is no larger than a MOD-2. Therefore such a height may be 10 to $60 \mathrm{~m}$ above the surface.

The mathematical models for surface layer turbulence are assumed to be fully applicable over a height range beginning at about $10 \mathrm{~m}$ above the surface and extending up to anywhere between $30 \mathrm{~m}$ and $150 \mathrm{~m}$, depending on the particular property in question and depending on the particular author.

Definition of the surface boundary layer and its depth requires that an arbitrary requirement be imposed. Panofsky and Dutton (1984) suggest that the layer in which certain vertical fluxes, such as that of horizontal momentum, vary by less than $10 \%$ be designated as the surface layer. The depth of this layer depends on wind speed, atmospheric stability and surface roughness. The authors suggest $100 \mathrm{~m}$ as an estimate, which should be particularly appropriate when consideration is restricted to operational wind speeds. Modeling of the layer above the surface boundary layer is less developed and requires more meteorological parameters. Therefore we recommend surface layer modeling exclusively for consideration in WT operations.

Operational wind speeds occur in the stable atmosphere and in the unstable atmosphere as well as in the neutral atmosphere. Modeling the stable atmosphere is the most uncertain of the three. Because our modeling will be limited specifically to a turbulence rms model, and because this property in the neutral atmosphere is an upper limit to that in the stable atmosphere, the rms model for the neutral atmosphere will be considered as a conservative upper limit to that for the stable atmosphere. That leaves specific rms models for the neutral and for the unstable atmosphere to be formulated. 
The mathematical formulation of an rms model for horizontal wind speed is expressed by:

$$
\sigma(z)=\left[U(z)\left(\frac{u_{\star}}{U(z)}\right)\right]\left\{\int_{0}^{\infty} \phi(n) F(n) d[\ln (n)]\right\}^{1 / 2}
$$

which applies at WT hub height $z$, and where:

$U(z)$ is the mean wind speed.

$u_{\star}$ is the friction velocity, assumed to apply over the height range of interest.

$n$ is circular frequency (in $\mathrm{H}_{\mathrm{Z}}$ )

$\phi(n)$ is the spectral distribution of horizontal wind speed fluctuations, $n S(n)$.

$F(n)$ is a filter corresponding to one of the data species mentioned in the report, such as undifferenced data from which a 30 minute running mean has been subtracted, or differenced data where the differencing interval is $1,3,10$, or 30 minutes. It follows that sigma is for the data species that corresponds to the particular specification of $F(n)$ that is used.

$\left(u_{\star} / U\right)$ is called turbulence intensity and is given by specific meterological equations for different atmospheric stabitities.

Models will be given for turbulence intensity and spectral distribution in the boundary layer. Also the filters will be defined.

\section{A. 1 TURBULENCE INTENSITY MODEL}

Turbulence intensity $\left[u_{\star} / U(z)\right]$ is a function of two dimensionless heights $z / z_{0}$ and $z / L . z_{0}$ is the surface roughness length. A table (Table A-1) of values is given below. The $L$ is the Monin-0bukhov stability length, (see Panofsky and Outton 1984.) The physics of this term is not easily grasped by non-meteorologists. Therefore it is not defined here. Suffice it to say that $L$ is infinite for neutral stability and is decreasingly positive for increasing stability and decreasingly negative for increasing instability. Therefore the dimensionless height $z / L$, zero for neutral stability, is increasingly negative for unstable conditions. An empirical method for estimating $L$ in the unstable atmosphere is given, see Equation $(A-5)$ and discussion. 
The complete model for turbulence intensity in the neutral and unstable atmosphere is written

$$
U * / U(z)=0.4 /\left[\ln \left(z / z_{0}\right)-\psi(x)\right]
$$

where

$$
\psi(x)=2 \ln \left(1+\frac{x}{2}\right)+\ln \left(1+\frac{x^{2}}{2}\right)-\tan ^{-1} x+\pi / 2
$$

and

$$
x=[1+16 z /(-L)]^{1 / 4}
$$

(see Paulson 1970). Note that $-L$ is positive for the unstable atmosphere.

Although the value of $z_{0}$ depends on both ground cover and terrain features at and near the site, most tables of values take only ground cover into consideration. Such a table is appended here from the review paper by

\begin{tabular}{|c|c|c|c|c|c|}
\hline Ground Cover & $z_{0}(\mathrm{~cm})$ & Ground Cover & $\underline{z}_{0}(\mathrm{~cm})$ & Ground Cover & $\underline{z}_{0}(\mathrm{~cm})$ \\
\hline $\begin{array}{l}\text { Ice } \\
\text { Mud } \\
\text { Snow }\end{array}$ & $\begin{array}{l}0.001 \\
0.04 \\
0.1\end{array}$ & $\begin{array}{l}\text { Sea } \\
\text { Grass Crops } \\
\text { Rural }\end{array}$ & $\begin{array}{r}2 \\
5 \\
20\end{array}$ & $\begin{array}{l}\text { Rural Woods } \\
\text { Suburbs } \\
\text { Rough Urban }\end{array}$ & $\begin{array}{l}100 \\
150 \\
100-400\end{array}$ \\
\hline Short Grass & 0.1 & & & & \\
\hline
\end{tabular}
Counihan (1975).

TABLE A-1. Roughness Lengths (cm) According to Counihan (1975) 
Panofsky and Dutton (1984) give a longer table that takes terrain into account. The applicability of this model in the WT layer at a site when $z_{0}$ approaches one meter is somewhat doubtful because the $\operatorname{term} \ln \left(z / z_{0}\right)$ should not be used to describe the wind if $\left(z / z_{0}\right)$ is less than 50 (see Garrat 1980). Perhaps the best all-around value for a typical rural-agricultural complex is about $0.1 \mathrm{~m}$.

Appropriate evaluation of $-L$ depends on atmospheric instability at the time rather than on the location. In principle values of $-L$ can be obtained for any place and time from an anemometer capable of high speed sampling of both wind and temperature fluctuations. But in practice, the exacting vertical alignment requirements need more frequent monitoring of the instrument than is reasonable to expect. Therefore the best procedure is that $-\mathrm{L}$ be estimated by applying some rule-of-thumb depending on grossly observable conditions as opposed to current measurement. The estimate must be for a minimum values of $-L$ rather than a maximum value if a conservative estimate of turbulence intensity is to be obtained. This value will be called $-L_{\text {min }}$. The 1968 Kansas data, of which the most primary analysis is presented by Izumi 1971, was used to derive the matching of $-L$ and $U$ values shown in Figure $A-1$.

These data were taken in July when instability could well have been maximized. $U$ values are for the 11.3 measuring height used, since heights in the vicinity of $10 \mathrm{~m}$ are frequent?y chosen as a reference height. Therefore $U$ will be called $U_{\text {ref. }}$. The empirical curve drawn through the data is

$$
-L_{\min }=0.3\left(u_{\text {ref }}\right)^{2.5}
$$

when $-L_{\min }$ is in $m$ and $U_{\text {ref }}$ is in $m / s$. At times of the data when insolation is wel? below the maximum, $-L$ is still an increasing function of $U$, but is larger than $-L_{\text {min }}$, since the surface heat flux is less. Thus an additional factor applies when cooler temperatures prevail or when the sun angle is lower. Such a factor is not available in the literature. Therefore rough estimations will be recommended here. For temperatures no greater 
than $70^{\circ}$ Fahrenheit, $-L$ should probably be at least twice $-L_{\text {min }}$ when the solar angle is large. When the solar angle decreases, $-L$ should increase possibly by a factor up to 10 , beyond which further increase is hardiy meaningful.

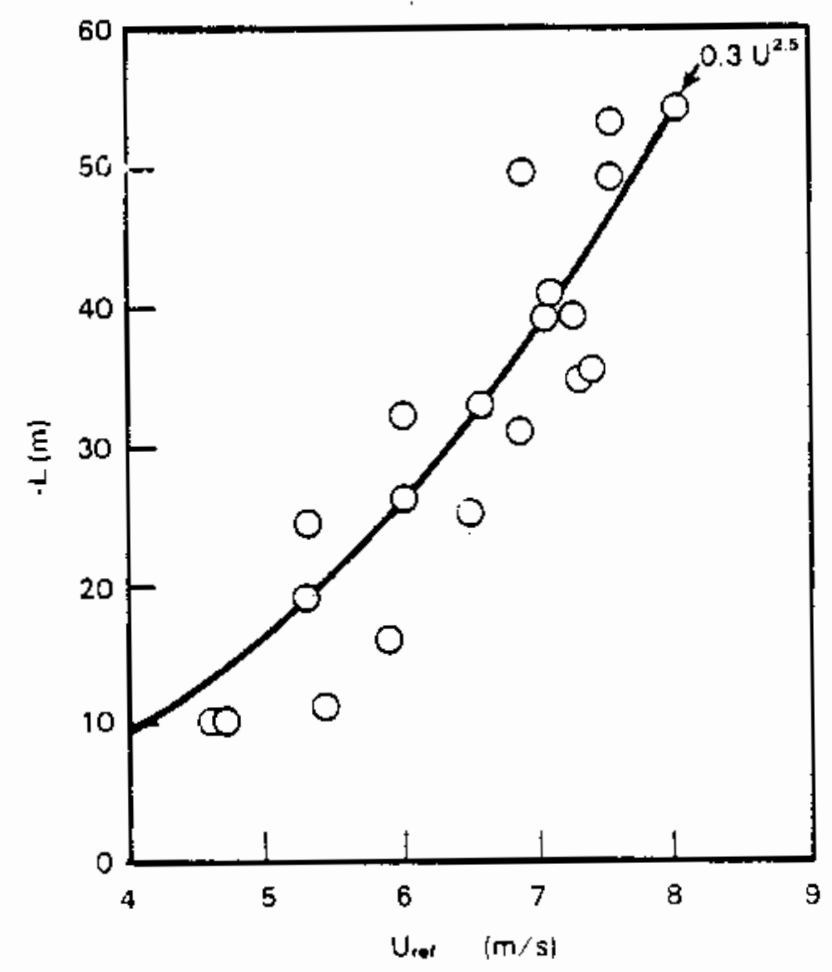

FIGURE A.1. Monin-Obukhov L Versus Mean Wind Speed, Unstable Atmosphere

There is an additional difficulty in determining $-L_{\text {min }}$ if $U(z)$ is known only at hub height and not at a reference height. In that case $U_{\text {ref }}$ must be calculated as a function of $U(z), z_{0}$ and an estimated value of $-L$. In this case, in order to avoid calculation that may be more iterative than it is accurate, values of $\left(U_{\text {ref }} / U(z)\right)$ may be assumed to be about 0.85 , 0.82 , or 0.80 depending on whether $Z$ is about 30,45 , or $60 \mathrm{~m}$. Actually 
these ratios are stronger functions of $z_{0}$ than they are of $Z$ or of $-L$. A table (Table A-2) of these ratios is given below. In the calculations producing these ratios the absolute values of $z / L$ was not allowed to exceed 1 , since the physical meaning of a larger value is questionable. Other suggestions for estimating $-L$ are given by Panofsky and Dutton (1984). 
TABLE A-2. Ratios $U_{\text {ref }} / U(z)$ for Selected values of $Z, z_{0}$, and $-L$

\begin{tabular}{|c|c|c|c|c|}
\hline \multirow{2}{*}{$z_{0}(a)$} & \multicolumn{4}{|c|}{$-L$} \\
\hline & $30 \mathrm{~m}$ & $60 \mathrm{~m}$ & $100 \mathrm{~m}$ & $200 \mathrm{~m}$ \\
\hline $\begin{array}{l}0.030 \\
0.100 \\
0.300\end{array}$ & $\begin{array}{l}0.893 \\
0.865 \\
0.823\end{array}$ & $\begin{array}{l}0.882 \\
0.854 \\
0.812\end{array}$ & $\begin{array}{l}0.874 \\
0.845 \\
0.802\end{array}$ & $\begin{array}{l}0.864 \\
0.833 \\
0.790\end{array}$ \\
\hline & \multicolumn{4}{|c|}{$-L$} \\
\hline$z_{0}{ }^{(b)}$ & $30 \mathrm{~m}$ & $60 \mathrm{~m}$ & $100 \mathrm{~m}$ & $200 \mathrm{~m}$ \\
\hline $\begin{array}{l}0.030 \\
0.100 \\
0.300\end{array}$ & $\begin{array}{l}0.835 \\
0.795 \\
0.738\end{array}$ & $\begin{array}{l}0.851 \\
0.816 \\
0.766\end{array}$ & $\begin{array}{l}0.841 \\
0.805 \\
0.755\end{array}$ & $\begin{array}{l}0.827 \\
0.790 \\
0.739\end{array}$ \\
\hline & \multicolumn{4}{|c|}{$-L$} \\
\hline$z_{0}{ }^{(c)}$ & $30 \pi$ & $60 \mathrm{~m}$ & $100 m$ & $200 \mathrm{~m}$ \\
\hline $\begin{array}{l}0.030 \\
0.100 \\
0.300\end{array}$ & $\begin{array}{l}0.798 \\
0.752 \\
0.687\end{array}$ & $\begin{array}{l}0.831 \\
0.793 \\
0.739\end{array}$ & $\begin{array}{l}0.820 \\
0.781 \\
0.727\end{array}$ & $\begin{array}{l}0.804 \\
0.764 \\
0.709\end{array}$ \\
\hline
\end{tabular}
(a) $z=30 m$
(b) $z=45 m$
(c) $z=60 m$

\section{A.2 THE SPECTRAL MODEL}

The spectral models for unstable and neutral conditions may be taken from the same equation by Højstrup (1981). Since his equation is for the alongwind component of turbulence, (called the $u$ component), we are assuming that the same spectrum and variance also apply to horizontal wind speed, as suggested by Powell and Connell (1980). The spectral equation is

$$
\frac{n S(n)}{u \star^{2}}=\frac{0.5 f_{j}}{1+2.2 f_{j} 5 / 3}\left(\frac{z_{i}}{-L}\right)^{2 / 3}+\frac{105 f}{(1+33 f)^{5 / 3}}
$$


where

$z_{i}$ is the depth of the convective layer, which is typically 1 or 2 kilometers on a sunny afternoon

$f$ and $f_{i}$ are dimensionless frequencies

$$
f=n z / U \quad f_{i}=n z_{j} / U \text {. }
$$

The curves for both addends are shown in Figure A-2 subject to arbitrarily chosen values of $-L$ and $z_{j}$. For unstable conditions the spectrum is the sum of the two curves.

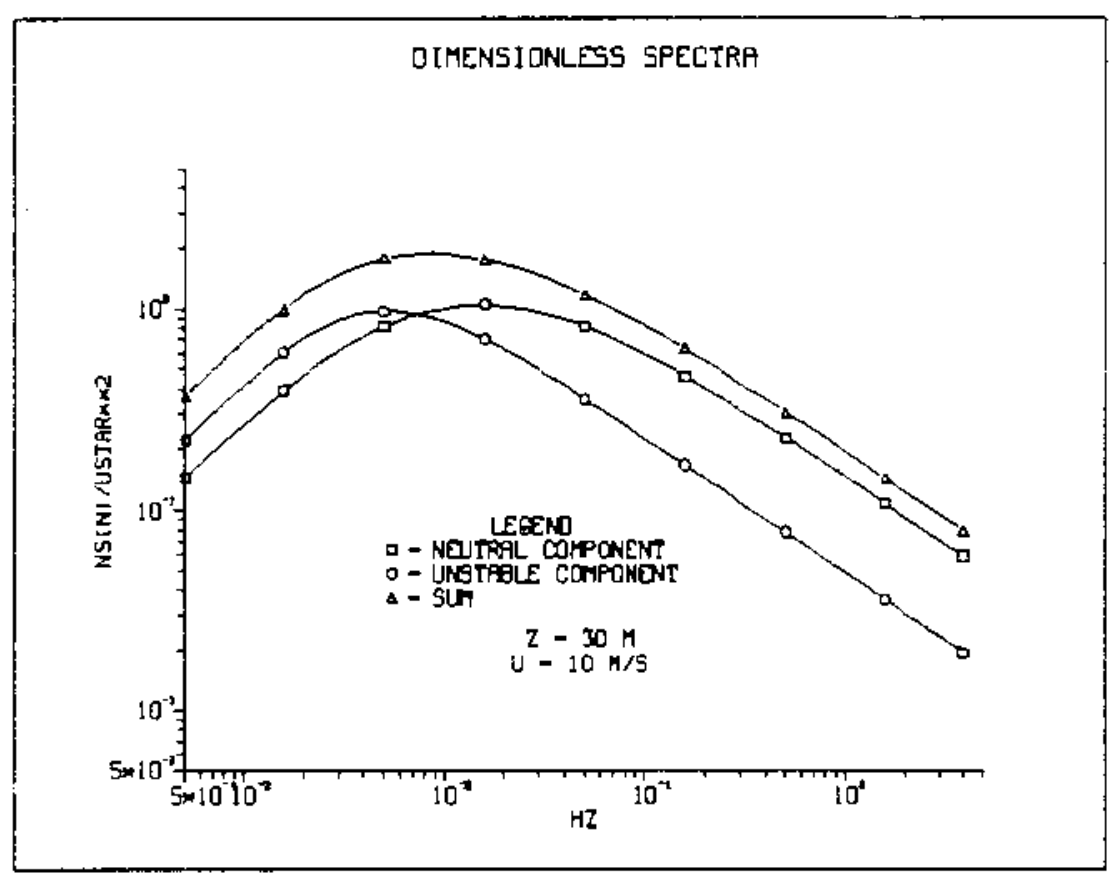

FIGURE A.2. Dimensionless u Spectra, Neutral and Unstable 
For neutral conditions, the first term in the spectral equation vanishes since $L$ is infinite. The remaining term is from Kaimal et al. (1972; see Eq 2.1.1-3). Use of the dimensionless frequency $f$ implies that within the kind of turbulence to which the second term applies, the length scales of turbulence are a direct function of height and are independent of mean wind speed. Use of $f_{j}$ implies that within the kind of turbulence to which the second term applies, the length scales of turbulence are directly proportional to the depth of the convective layer and are independent of mean wind speed and height.

The most practical means of obtaining suitable values for $z_{j}$ is that of estimation by formula. During sunny days when the atmosphere is unstable, the depth of the convective layer increases to a maximum in late afternoon and disintegrates about an hour before sunset. Maximum afternoon values are given by Holzworth (1972) in a series of maps of isopleths over the U.S., one map for each season. Also morning values are given for each season. A suggested formula for $z_{j}$ as a function of time of day is

$$
\begin{array}{cc}
z_{i}=M V+(A V-M V) & \sin [\pi(\text { hour }-10) / 12] \\
\text { hour between } & 1000 \text { and } 1600 \\
z_{i}=M V & \text { before } 1000 \\
z_{i}=A V & \text { after } 1600,
\end{array}
$$

where $M V$ is a Holzworth morning value and $A V$ is a Holzworth afternoon value. The afternoon values minimize over New England and maximize somewhere in the vicinity of the four corners area. The morning values exhibit no such regularity. Since use of the above formula is likely to be more sensitive to error in afternoon values rather than in morning values, the latter will be more carefully specified. Suggested morning values are:

$\begin{array}{ll}\text { Winter } & 600 \mathrm{~m} \\ \text { Spring } & 600 \mathrm{~m} \\ \text { Summer } & 400 \mathrm{~m} \\ \text { Autumn } & 300 \mathrm{~m} .\end{array}$


Within 25 miles of any coast, values twice as large are appropriate. Suggested afternoon values are given in Table A.3.

TABLE A-3. Suggested Afternoon Values for $z_{j}$

\begin{tabular}{|c|c|c|c|}
\hline \multirow[b]{2}{*}{ Season } & \multicolumn{3}{|c|}{ Geographic Values (m) } \\
\hline & Minimum & Maximum & Typical $^{(a)}$ \\
\hline Winter & 500 & 1500 & 1000 \\
\hline Spring & 1000 & 3400 & 1600 \\
\hline Summer & 600 & 4000 & 1800 \\
\hline Autumn & 800 & 2400 & 1300 \\
\hline
\end{tabular}

(a) East of Mississippi River

\section{A.3 THE FILTER MODEL}

- We now consider data which has been averaged over a period $T_{a}$ and which is either 1 ) the result of subtracting a running mean of length $T_{m}$ from the original data or 2) the result of differencing the data at an interval $\Delta t$. For these two cases the compiete filter specifications are:

$$
\begin{aligned}
& \text { 1) } F(n)=\left[1-\operatorname{sinc}^{2}\left(n \pi T_{m}\right)\right] \operatorname{sinc}^{2}\left(n \pi T_{a}\right) \\
& \text { 2) } \left.F(n)=\sin ^{2}(n \Delta t) \operatorname{sinc}^{2}\left(n \pi T_{a}\right) / / \Delta t\right)^{2}
\end{aligned}
$$

where $\operatorname{sinc}(x)=\sin (x) / x$.

The use of $\Delta t^{-2}$ converts the differenced data from velocities to acceleration for the user. 


\section{A.4 SENSITIVITY TESTING}

This section shows how much the calcuiated rms values vary with variation of the aforementioned conditions. For this purpose we establish a base case, calculate the rms value, and then calculate rms values for variation about that base case. Actually this is done about one base neutral case and one base unstable case. For all cases the following are used:

$$
\begin{aligned}
z & =60 \mathrm{~m} \\
U(z) & =8 \mathrm{~m} / \mathrm{s} \\
T_{a} & =60 \mathrm{~s} .
\end{aligned}
$$

Other base case values are

$$
\begin{aligned}
& z_{0}=0.10 \mathrm{~m} \\
& -L=100 \mathrm{~m} \\
& z_{i}=1800 \mathrm{~m} .
\end{aligned}
$$

Of course the last two values are used only in the modeling of the unstable atmosphere.

It is further pointed out that all values apply to minute-averaged data that are first high pass filtered by subtracting out a 30 -min running mean.

For the base case test, the rms value was $0.73 \mathrm{~m} / \mathrm{s}$. For the other tests, the ratio of calculated $\mathrm{ms}$ to this value for each test is as given below. For the rms applying to the unstable atmosphere, two ratios are given; one to the base rms for the neutral atmosphere and one to the base rms for the unstable atmosphere. That is, in the table (Table A-4) following:

$$
\begin{aligned}
\text { ratio }= & \text { rms predicted by model for particular parameterization/ } \\
& \text { rms predicted by model for base case parameterization for } \\
& \text { the neutral or the unstable atmosphere, as specified in the table. }
\end{aligned}
$$


TABLE A.4. Distinctions between Neutral and Unstable Atmosphere

THE NEUTRAL ATMOSPHERE

$\begin{array}{ll}\frac{z_{0}(\mathrm{~m})}{0.03} & \text { Ratio } \\ 0.10 & 0.84 \\ 0.30 & 1.00 \\ & 1.21\end{array}$

THE UNSTABLE ATMOSPHERE

$\begin{array}{lcccc}\underline{z} 0(\mathrm{~m}) & \underline{-\mathrm{L}(\mathrm{m})} & \underline{\underline{z} i \underline{(m)}} & \begin{array}{c}\text { Ratio-to-Neutral } \\ \text { Base Value }\end{array} & \begin{array}{c}\text { Ratio-to-Unstable } \\ \text { Base Value }\end{array} \\ 0.10 & 100 & 1800 & 1.67 & 1.00 \\ 0.03 & 100 & 1800 & 1.37 & .82 \\ 0.30 & 100 & 1800 & 2.09 & 1.25 \\ 0.10 & 50 & 1800 & 2.03 & 1.22 \\ 0.10 & 200 & 1800 & 1.43 & .86 \\ 0.10 & 100 & 1000 & 1.45 & .87 \\ 0.10 & 100 & 2700 & 1.86 & \end{array}$

These figures indicate that the most important distinction of all those given is that differentiating between the neutral atmosphere and the unstable atmosphere. 